\title{
Analysis on the Violin Performance in Symphony
}

\author{
Rui Zhang ${ }^{1, a}$, Hui Hui $\mathrm{Ji}^{2, b}$ \\ ${ }^{1}$ Institute of Art of Shandong University(Weihai), China \\ ${ }^{2}$ Institute of Art of Shandong University(Weihai), China \\ a705658299@qq.com
}

Keywords: Violin; Performance; Symphony

\begin{abstract}
As a kind of western musical instrument, the violin itself has a unique artistic charm. While In the symphony orchestra, the violin makes great contributions to the whole team through a full play of itself. As a kind of large-scale orchestral music, there are some indispensable parts in symphony: such as the string music, the wind instrument, the percussion music, the color instrument, and etc. And, as a kind of stringed instrument, relying on its own unique sound, the violin has shown distinctive auditory feast for the audience in a symphony. Therefore, this article mainly analyzes the significance of violin in the symphony and further puts forward its playing and training in symphony, providing certain reference to further research on the violin performance.
\end{abstract}

\section{Introduction}

As a kind of orchestral instrument, relying on its own the beautiful music, the violin plays a positive role in symphony and makes great contributions to the overall effect of the band. So, the author mainly focuses on the methodology of this and proposes its way of performing and training in symphony, which enables people to have more in-depth understanding of the violin and makes that more reasonable, thus gaining a positive development in our country.

\section{The Significance of the Violin in the Orchestra Performance}

First of all, as a kind of bowed string instrument, the violin plays an important role in the orchestra, a main part in symphony. As a kind of presided instrument, it serves as basis, a core role in the whole band. For example, "the Butterfly lovers", a familiar work known to everyone and a kind of violin concerto, the background of which may be perfectly performed with the aid of violin, bringing people a unprecedented shock. Moreover, the Heroic Symphony of Beethoven, Tchaikovsky's" Romeo and Juliet ", etc. of which the emotion and beautiful melody can actively be presented through the violin, together with other instruments. Secondly, it provides cadenza for the band, as for which it mainly means the application of movement in the end. At this time, the going may suspended to make way for one musical instrument alone, etc. this process is even harder, as it is a kind of improvisation, etc. For a violinist, it is time to show his own unique form of music performance, during which involved emotion will be vividly shown, making the atmosphere of the scene sometimes quiet, sometimes riot. Strauss, for example, the variation of rimsky-korsakov suite "s haier Sartre" and so on, are played this way, bringing unique experience for concerto and making the whole symphony more complete, through which they have achieved unparalleled success. As a violinist, one needs to act differently according to different work style, through such varieties, the emotion of the composer of can vividly be acted, so do the spiritual world of those characters, which offers great help to the whole performance 


\section{Advisable Suggestions on the Harmony Betweenthe Violin and the Symphony}

For the time being, during the process of violin teaching, more attention has been paid to the left hand while less to the left one. For those performers, the role of the right hand is also very important, which is regarded as necessary while using the bow, therefore, in the process of training, training can be carried out from the right hand. To effectively improve the performance of the right hand, the violinist, should on the one hand, set higher standards on the bow training thus to improve the bow proficiency of it. In addition, the position you're drawing the bow should be consistent each time and go on performance at the same place while in training. On the other hand, there are also certain requirements on the bow speed, it is necessary to strengthen the training at slow and at fast speed, which can make players feel the constant change during the bow training, thus promoting bow rhythm and increasing proficiency, yet familiarity with every part of the bow seems necessary. In addition, during a real show, through perfectly showed tone and pitch, the degree of splendidness may gain a great increase. Finally, in general, in the process of practice at ordinary times, there is the need to for players to train skipping the bow, in the process, it is supposed to be strengthened, during which chances are available for a good control of time and height, and also more perfectly performance is also improvement for the players.

Strengthen the Training of Left-hand. For violinists, left-hand performance is mainly fingering training. Violin is perfect performer, which can not only perfectly show different tones, but also give a person the enjoyment of beauty. From another perspective, the instrumental ensemble is a bit more difficult, and it needs to improve the intonation training ability of players in more complex movement, Therefore, in the process of daily practice, developing players' understanding of the whole work in terms of intonation and taste is necessary, for harmony is of great use in a team performance. Once one performer is off-track, the whole play would be lack of harmony. Besides, for those difficult pieces, practice slowly firstly and then fast to successfully seize different intonations, In addition, guidance should be provided for players to stop the sound thus to make its own integrated into the whole movement of the play, making the play more harmonious. At the same time, it is necessary for violinists to train the ability of serving as a foil to each other, such as high voice and low voice. Besides, in training the left hand there provides a chance for softer pieces, during which proper choices are indispensable in order to make the performance more perfect.

Strengthen Understanding in Commanding. In the process of playing the violin, rhythm control needs to be strengthened. However, different commanders are of different styles, if the violinist lacks the ability to actively understand the intention of different commanders and unable to follow the tempo, then chaos in the play may not be avoided. Besides, there has shown comparatively remarkable difference between the commander at the scene and usual command in most cases .which will not only influence the understanding and control of the rhythm but also the speed and the volume of sound. Therefore, as a violinist, he should be calm, take better control of the right rhythm and be clear about the beats of the commander, with which the intentions would be well understood. Thus, it's very important for the violinists to properly increase the comprehension ability in the performance, which helps develop training ability normally and promotes ability in formal cases. Finally, for a player, one should strengthen their own ideological content. To do this, he is supposed to achieve the unification between his career and art performance, the individual consciousness and the collective consciousness, through which he will be able to shock the spiritually, thus to show a high level of performance and make great progress for the whole band.

Promote the Harmony Between Performing Skills and Acoustics Effects. As for symphony performance, skills are absolutely important, but there is still the need to strengthen the harmonious 
unification with acoustics, which is also a standard in a full playing. So in symphony, there should have certain cooperation and understanding between different instruments, only through perfect unification, can the overall effects be more perfectly presented, by which emotions involved can be positively captured, making the audience in. In addition, although high and exquisite expression ability it has in itself, still each instrument needs to be well coordinated in the whole symphony with acoustic blending in, so as to make the sound more clearly presented. As a violinist, one should therefore actively give a full play of itself, so that he can let the audience feel fascinated about music, and make them appreciate the exquisite interpretation deeply.

\section{Conclusion:}

To sum up, in the symphony orchestra, the violin plays its positive role--it adds vitality to the overall effects by leading and brings people a good sense of auditory appreciation. Therefore, as a violinist, one should actively improve their performance level and skill, pay attention to the training of the left hand and the right hand, and strengthen its own skill as well as the unification with the whole symphony orchestra, in order to promote the level of violin performance; In addition, more emotion should be involved so as to make the work perfectly and emotionally presented, making people integrated and therefore shocked.

\section{References:}

[1]Wangyi, the charming and quality of the violin[J]. Art technology, 2016, (02): 216-217.

[2]Lu Chunyan, Solutions to normal questions in violin teaching[J], Fujian education, 2015, (Z2): 25-27.

[3]Che cingyuan, Analysis on the development and innovation application the violin in its artistic career in homeland[J]. Normal songs, 2015, (01): 66-68.

[4]Li qinghua. Study on sight-reading consciousness for violinists in symphony[J].Science and Technology Innovation Herald, 2013, (09): 33-35.

[5]Liuwei, Study on violinists’ sight-reading in symphony[J].Grand music, 2014, (09): 267-268. 